\title{
Thermal stability analysis of particles incorporated in cirrus crystals and of non-activated particles in between the cirrus crystals: comparing clean and polluted air masses
}

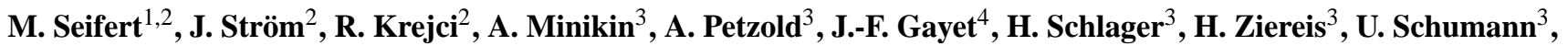 \\ and J. Ovarlez ${ }^{5}$ \\ ${ }^{1}$ Department of Meteorology, Stockholm University, Stockholm, Sweden \\ ${ }^{2}$ Air Pollution Laboratory, Institute for Applied Environmental Research, Stockholm University, Stockholm, Sweden \\ ${ }^{3}$ Deutsches Zentrum für Luft- und Raumfahrt, Institut für Physik der Atmosphäre, Oberpfaffenhofen, Germany \\ ${ }^{4}$ Laboratoire de Météorologie Physique, Université Blaise Pascal, Clermont-Ferrand, France \\ ${ }^{5}$ Laboratoire de Météorologie Dynamique, Ecole Polytechnique, Palaiseau, France
}

Received: 5 May 2003 - Published in Atmos. Chem. Phys. Discuss.: 17 July 2003

Revised: 10 August 2004 - Accepted: 11 August 2004 - Published: 23 August 2004

\begin{abstract}
A thermal volatility technique is used to provide indirect information about the chemical composition of the aerosol involved in cirrus cloud formation. The fraction of particles that disappears after being heated to $125^{\circ} \mathrm{C}$ is termed volatile and the fraction that disappears between 125 and $250^{\circ} \mathrm{C}$ is termed semi-volatile. Particles that still remain after being heated to $250^{\circ} \mathrm{C}$ make up the non-volatile fraction. The thermal composition of residual particles remaining from evaporated cirrus crystals is presented and compared to interstitial aerosol particles (non-activated particles in between the cirrus crystals) for two temperature regimes (cold: $\mathrm{T}<-38^{\circ} \mathrm{C}$, warm: $-38 \leq \mathrm{T}<-23^{\circ} \mathrm{C}$ ), based on insitu observations. The observations were conducted in cirrus clouds in the Southern Hemisphere (SH) and Northern Hemisphere $(\mathrm{NH})$ midlatitudes during the INCA project. In the cold temperature regime, the non-volatile fraction of the residual particles was typically in the range 10 to $30 \%$ in the $\mathrm{NH}$ and 30 to $40 \%$ in the $\mathrm{SH}$. In the warm temperature regime, the non-volatile residual fraction was typically 10 to $30 \%(\mathrm{NH})$ and 20 to $40 \%$ (SH). At high crystal number densities the non-volatile fraction in both temperature regimes was even higher: in the range of 30 to $40 \%(\mathrm{NH})$ and 40 to $50 \%$ (SH). The semi-volatile fraction was typically less than $10 \%$ in both hemispheres, causing the volatile fraction to essentially be a complement to the non-volatile fraction. In terms of the fractioning into the three types of particles, the SH cold case is clearly different compared to the other three cases (the two warm cases and the cold NH case), which
\end{abstract}

Correspondence to: $\mathrm{M}$. Seifert

(marco_seifert@hotmail.com) share many features. In the NH data the distribution of different particle types does not seem to be temperature dependent. In all the cases, the non-volatile fraction is enriched in the residual particles compared to the fractions observed for the interstitial particles. This enrichment corresponds to about $15(\mathrm{NH})$ and $30(\mathrm{SH})$ percent units in the two cold cases and to 15-25 (NH) and 25-35 (SH) percent units in the two warm cases. In the NH cold case, there is a clear relation between the fractions observed in the interstitial particles and what is observed in the residual particles. The observed large fractions of non-volatile particles show that particles forming ice crystals are not entirely made up of water-soluble sulfate particles.

\section{Introduction}

Indirect climate forcing can be viewed as a series of microphysical processes that connect anthropogenic emissions to changes in cloud albedo and cloud occurrence. A more detailed understanding of the properties of the cloud forming particles such as Cloud Condensation Nuclei $(\mathrm{CCN})$ and Ice Nuclei (IN) is important for assessing natural and anthropogenic impacts by aerosols on clouds and climate. While the aerosol induced change in cloud droplet spectrum in low clouds has been studied extensively and the formation of warm clouds is relatively well understood, the formation of ice crystals is rather complex and the role of the aerosol remains uncertain. This is mainly due to the fact that ice crystals may form through two different processes: homogeneous and heterogeneous nucleation. The relative role of different 
modes of ice nucleation is still a matter of debate but is thought to critically depend on temperature (DeMott, 2002). Presumably homogeneous nucleation (freezing of a solution droplet) dominates at low temperatures $\left(\mathrm{T}<-38^{\circ} \mathrm{C}\right)$, but heterogeneous nucleation (an IN initiates freezing) can become important at higher temperatures, in weaker updrafts or in the presence of large numbers of IN (DeMott et al. 1997; Sassen and Benson, 2000; Kärcher and Lohmann, 2003).

Our knowledge about cirrus from in-situ data is to a large extent based on the FIRE, SUCCESS, EUCREX, ICE, AEROCONTRAIL and INTACC experiments. These projects focused mainly on the Northern Hemisphere $(\mathrm{NH})$ midlatitudes leaving a gap of data in the Southern Hemisphere (SH) midlatitudes. With the project INCA (Interhemispheric differences in cirrus properties from anthropogenic emissions) cirrus observations became for the first time available in the SH hemisphere midlatitudes that allow the comparison of clouds in two, with respect to anthropogenic emissions, very different regions of the world under comparable meteorological conditions. One of the first results presented from the INCA experiment was a comparison of aerosol number densities in the UT during the two INCA campaigns in out-ofcloud environments (Minikin et al., 2003). As expected, the midlatitudes $\left(50^{\circ}-60^{\circ}\right)$ of the $\mathrm{SH}$ proved to be a rather pristine region with an average ultrafine aerosol number density of $350 \mathrm{~cm}^{-3}$ compared to $1400 \mathrm{~cm}^{-3}$ in the NH. Refractory aerosol particles, which may act as heterogeneous ice nuclei, were found to be in the order of 35 and $12 \mathrm{~cm}^{-3}$ in the $\mathrm{NH}$ and $\mathrm{SH}$, respectively. Based on the observed differences in aerosol properties between the $\mathrm{NH}$ and $\mathrm{SH}$ in cloud free environments one might speculate if this is also reflected in the properties of the aerosol that is involved in cirrus formation.

The more details we learn about the nature of the aerosols that form cirrus clouds the more intriguing the mechanisms appear. Seifert et al. (2003a) showed that the number density of particles contained in cirrus crystals was controlled by particles smaller than $0.1 \mu \mathrm{m}$ in diameter. On the other hand, the volume density was dominated by particles larger than $0.1 \mu \mathrm{m}$. These particular features presented only small differences between observations performed in the pristine Southern Hemisphere (SH) midlatitudes and observations performed in the more polluted Northern Hemisphere (NH) midlatitudes. Seifert et al. (2004) showed that the crystal number density did not increase monotonically with increasing aerosol number density, and that there is a mean crystal number density maximum around $2 \mathrm{~cm}^{-3}$ in the aerosol number density range 100 to $200 \mathrm{~cm}^{-3}$. Also, with respect to these findings, the pristine and more polluted environments presented more similarities than differences. In contrast to the small differences between $\mathrm{SH}$ and $\mathrm{NH}$ mentioned above, Ström et al. (2003) and Haag et al. (2003) concluded that the cirrus formation threshold with respect to relative humidity over ice was in the range of 20 to $25 \%$ units lower in the $\mathrm{NH}$ midlatitudes compared to the $\mathrm{SH}$. The formation threshold for the SH was consistent with homogeneous nucleation.
The chemical composition of the ice forming particles is one of the least understood aspects of cirrus clouds. Recently, Murphy et al. (1998) have shown the composition of upper tropospheric aerosol to be very diverse, challenging the traditional view that aerosol composition in the upper troposphere is dominated by sulfates. The chemistry of aerosol particles incorporated in ice crystals during cloud formation might therefore be more complex than previously treated by most numerical simulations. Heintzenberg et al. (1996) and Twohy and Gandrud (1998) using single particle analysis, showed that minerals dominated the composition of particles larger than a few hundred nanometers in diameter. However, compared to the total population of ice forming particles, these rather large particles are very few.

To explore the chemical composition of smaller particles, we deployed for the first time the thermal volatility technique coupled to a CVI (Counterflow Virtual Impactor). This technique provides no direct information about the chemical composition, but offers a method to investigate the thermal stability of particles in the size range that controls the crystal number density. We contrast observations made in the pristine environment of the SH to observations performed in the more polluted $\mathrm{NH}$ midlatitudes.

\section{Experimental}

The INCA project included two field campaigns in Punta Arenas, Chile $\left(54^{\circ} \mathrm{S}\right)$ and Prestwick, Scotland $\left(53^{\circ} \mathrm{N}\right)$. The Punta Arenas campaign (10 flights) was performed in March/April 2000 and the second campaign (9 flights) from Prestwick was conducted in September/October 2000. This made the seasons equivalent. The aircraft Falcon, operated by Deutsches Zentrum für Luft- und Raumfahrt, was extensively equipped with instrumentation to measure aerosol and cloud microphysics. In addition, a trace gas payload was also deployed to characterize air masses. Tracers used in this study were limited to water vapor, $\mathrm{CO}$ and $\mathrm{O}_{3}$.

\subsection{Instrumentation}

\subsubsection{Sampling inlets and cloud probes}

Cirrus crystals were sampled using a Counterflow Virtual Impactor (CVI) inlet. The CVI is a device which inertially separates cloud elements larger than about $5 \mu \mathrm{m}$ and smaller than about $60 \mu \mathrm{m}$ (aerodynamic size) in diameter from the surrounding atmospheric air (Ogren et al., 1985; Noone et al., 1988). Residual particles left behind by the evaporating cloud elements are analyzed downstream of the inlet. Each crystal is assumed to leave only one residual particle behind, which has proven to be a valid assumption (Seifert et al., 2003a). The design of the CVI probe causes an enrichment of the crystal number density in the sample air compared to ambient conditions (Ogren et al., 1985; Noone et al., 1988). The enrichment factor was typically around 150 . Hence, residual 
number densities are originally enhanced, but all data presented in this study has been corrected back to ambient conditions.

Aerosol particles were sampled with a $1 / 4$ inch stainless steel tube with the opening turned opposite to the flight direction. Due to inertia, large particles pass by the probe and only small particles $(\mathrm{Dp}<1 \mu \mathrm{m})$ enter the sample flow (Schröder and Ström, 1997).

The Polar Nephelometer probe is designed to measure the optical parameters of clouds containing either water droplets or ice crystals, or a mixture of these particles. The sensor measures the scattering phase function of an ensemble of cloud particles intersecting a collimated laser beam (Gayet et al., 1997). With the direct measurement of the scattering phase function cloud optical parameters can be calculated, making it possible to distinguish between water droplets and ice particles.

\subsubsection{Residual and interstitial aerosol properties}

Inside the aircraft, sample air is fed into three separate branches for thermal discrimination. The first branch is not actively heated and the sampling line is at cabin temperature, which is approximately 25 to $30^{\circ} \mathrm{C}$. The other two branches are heated to 125 and $250^{\circ} \mathrm{C}$, respectively. Following this, the number density of the remaining particles in each branch is determined by CPCs and referred to as $\mathrm{N}_{30}\left(\mathrm{~T} \approx 25-30^{\circ} \mathrm{C}\right)$, $\mathrm{N}_{125}\left(\mathrm{~T}=125^{\circ} \mathrm{C}\right)$ and $\mathrm{N}_{250}\left(\mathrm{~T}=250^{\circ} \mathrm{C}\right)$.

Two of these thermal denuder systems were used, one for the residual particles from the CVI probe, and the other for the interstitial and out-of-cloud aerosol. The interstitial aerosol lines were connected to four CPCs (model TSI 3010). The particle counters connected to the non-volatile and semivolatile branches had a cut-off at $10 \mathrm{~nm}$. The two particle counters connected to the interstitial not actively heated branch had cut-offs at 5 and $14 \mathrm{~nm}$, respectively. To overcome this problem of different cut-offs, an average between these two CPCs was used to emulate a counter with a cutoff comparable to the two other heated branches. The approximated number density of interstitial aerosol particles larger than $10 \mathrm{~nm}$ in the not actively heated branch will be referred to as the interstitial aerosol number density (Nint). For the residuals the not actively heated CVI sampling line was connected to a CPC model TSI 3010 with cut-off at $10 \mathrm{~nm}$. The total residual number density (not actively heated sample line) is referred to as Ncvi. The two heated sample lines were connected to modified CPCs (model TSI 3760) using forced cooling (Schröder and Ström, 1997). Post campaign laboratory calibration showed that the TSI 3010 and the two modified TSI 3760 had the same $50 \%$ efficiency cut-offs, but the slope of the efficiency curve was flatter for the two modified counters.

The thermal denuder technique provides indirect information about the chemical composition of the aerosol (Clarke, 1991). If particles disappear at $125^{\circ} \mathrm{C}$ the composition is consistent with sulfuric acid and some organic species. If the particles disappear at $250^{\circ} \mathrm{C}$ the composition is consistent with ammonium sulfate or ammonium bi-sulfate. If particles still remain after heating to $250^{\circ} \mathrm{C}$ the composition is consistent with e.g. minerals, soot, or sea salt. Note that we do not know what the particles are made of, only that their thermal stability is consistent with the various types of compounds mentioned. By comparing the different number densities $\left(\mathrm{D}_{p}>10 \mathrm{~nm}\right)$, we can derive three fractions $\left(\mathrm{N}_{30}-\mathrm{N}_{125}\right) / \mathrm{N}_{30}$, $\left(\mathrm{N}_{125}-\mathrm{N}_{250}\right) / \mathrm{N}_{30}$ and $\mathrm{N}_{250} / \mathrm{N}_{30}$, which are referred to as the volatile, semi-volatile and non-volatile fractions.

Volatility analysis is based on the fact that many aerosol species dissociate and evaporate at characteristic temperatures. As an aerosol is heated particles lose mass as their chemical constituents volatilize resulting in changes in the size distribution. For an externally mixed aerosol the change in size distribution is characterized by the removal of particles arising from the same source. For an internally mixed aerosol the interpretation of the volatility data is not straightforward. Increasing the temperature causes volatile species to disappear, but may also cause the physical separation of particle constituents. Hence thermal treatment may (1) shift the size spectrum to smaller diameters but the number density stays constant, (2) shift the size spectrum to smaller diameters but the number density increases (when volatile material in between two or more non-volatile inclusions evaporates) or (3) shift the size spectrum to smaller sizes and the number density decreases. The complex thermal behavior of an internally mixed aerosol has been recently investigated by Brooks et al. (2002). The simple thermal denuder system used in this study is limited by only treating number densities. We do not know the relative amounts by mass of volatile, semi-volatile and non-volatile material in a particle in other words the mixing of the particle. Hence we cannot distinguish between a particle that contains a non-volatile core and a particle entirely made up of non-volatile material.

\subsubsection{Trace gases}

Relative humidity was measured by a cryogenic frost point hygrometer (Ovarlez et al., 2000). From the primary measurement of the frost point we derived the relative humidity over ice, which will be referred to as RHi. In addition we made use of $\mathrm{CO}$ to identify recent transport of polluted air from the boundary layer and $\mathrm{O}_{3}$ to identify the likely influence of stratospheric air. The instruments used have already been described (Gerbig et al., 1996; Schlager et al., 1997).

Data is stored at $1 \mathrm{~Hz}$. In order to smooth the data we applied a $6 \mathrm{~s}$ moving average to the data while still preserving much of the temporal resolution.

\subsection{Data selection}

The data sets used in this study were selected to represent cirrus observations in the upper troposphere and tropopause 

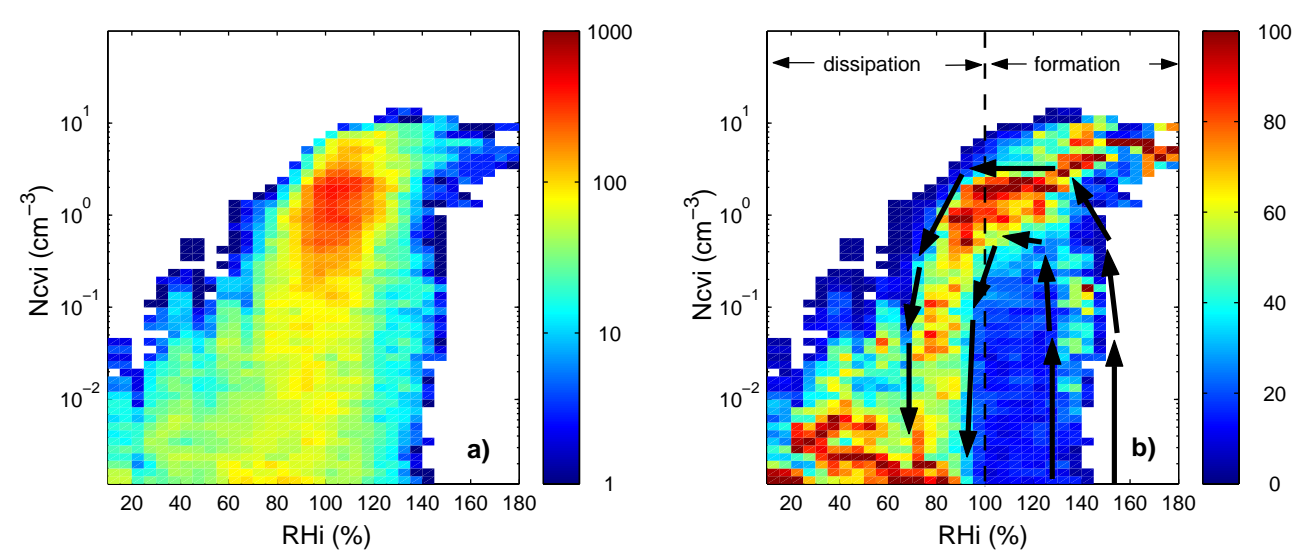

Fig. 1. (a) the frequency distribution of observations as function of RHi and Ncvi. Color scale represents number of observations. (b) same data as in left plot but normalized to the maximum value for each given RHi. Color scale is in percent. Data from the Prestwick campaign (cold: $\mathrm{T}<-38^{\circ} \mathrm{C}$ ).

region. Stratospheric observations were excluded based on ozone profiles, and only measurements made above $6 \mathrm{~km}$ altitude and below $-23^{\circ} \mathrm{C}$ temperature were used. A minimum crystal number density of $0.001 \mathrm{~cm}^{-3}$ was used to separate between cloudy and non-cloudy data points. Incloud data points with the presence of liquid water, observed down to $-34^{\circ} \mathrm{C}$, were excluded based on the Polar Nephelometer measurements. Finally, the influence by polluted air masses recently transported from the boundary layer (i.e. via convective clouds) was reduced by excluding data points where the $\mathrm{CO}$ mixing ratios exceeded $90 \mathrm{ppbv}$. The remaining data, $21 \mathrm{~h}$ from the $\mathrm{SH}$ and $12 \mathrm{~h}$ from the $\mathrm{NH}$, was divided into two temperature regimes (cold: $\mathrm{T}<-38^{\circ} \mathrm{C}$ and warm: $-38 \leq \mathrm{T}<-23^{\circ} \mathrm{C}$ ). This temperature division is based on the notion that the mode of freezing at temperatures below ca. $-38^{\circ} \mathrm{C}$ is expected to be dominated by homogeneous nucleation. Note that warm temperature data makes up for less than $20 \%$ of the total observation time in both hemispheres.

\section{Results}

\subsection{Lifecycle of a cloud}

Recently, Ström et al. (2002) suggested a novel way of presenting data that relates an observed parameter to what particular phase of the cloud lifecycle the measurements are performed at. This is simply done by plotting the parameter of interest as a function of relative humidity and crystal number density. Following this concept Seifert et al. (2004) studied observations of vertical wind for the INCA data. Positive vertical velocities were found to be predominately associated with relative humidities above $100 \% \mathrm{RHi}$, whereas negative vertical velocities were found to be predominately associated with relative humidities below $100 \%$ RHi. In this study we plot the frequency of observations as a function of Ncvi and RHi. Figure 1a can be viewed as a probability plot for finding a specific combination of crystal number density and relative humidity. Because there is a very large range in probability the surface is plotted on a logarithmic scale. Nevertheless, a maximum in the observations is located around $\mathrm{Ncvi}=2 \mathrm{~cm}^{-3}$ and $\mathrm{RHi}=100 \%$, which is the most probable combination to observe in a cloud based on the INCA campaign data. Data at the very lowest relative humidities should be considered with caution since it may arrive from flight segments across cloud edges and where memory effects may cause artifacts.

Following an air parcel any cirrus cloud must begin its life cycle in the lower right part of the Ncvi, RHi diagram, because at the point of formation the humidity must be at least above $100 \%$ RHi and the crystal number density low. At the end of the life cycle the cloud must be in the lower left part of the diagram, because the relative humidity must be at least below $100 \%$ RHi and the crystal number density must be low. Thus we have the starting point and the end point. Exactly, how an individual cloud will move in the Ncvi, RHi diagram from the lower right side to the lower left side depends on variables such as the presence of suitable ice forming particles, water vapor and updraft velocity.

Although we don't know the details there are some general properties about the cloud that might be helpful in interpreting the data. Once ice mass has formed, the cloud starts to deplete available water vapor. A peak crystal number density will be reached and the the cloud will begin moving from right to left in the diagram. A cloud forming few crystals will move close to the base line, whereas a cloud forming many crystals must move up in the diagram and to the left. How far up it reaches depends on mainly the updraft velocity. How strong the component to the left is, depends both of the updraft speed and the ice mass (crystal number density). Thus in the beginning of the lifecycle the cloud increase crystal number density without reducing the relative humidity very much (the relative humidity may even increase while crystals form if the updraft is strong enough). Once the peak 

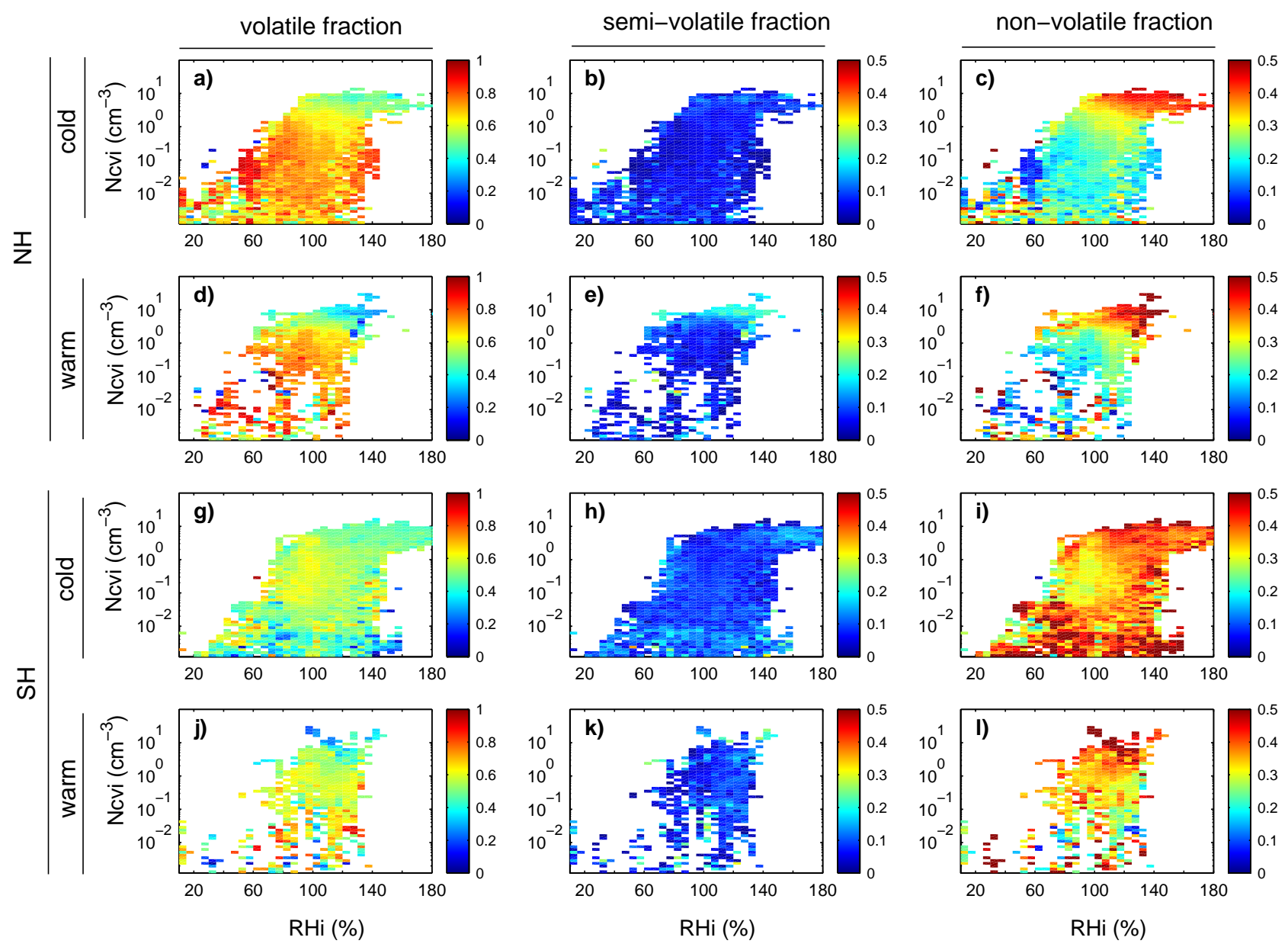

Fig. 2. Average volatile (left column), semi-volatile (middle column) and non-volatile (right column) residual particle fraction as a function of RHi and Ncvi. Data divided into campaign ( $\mathrm{NH}, \mathrm{SH}$ ) and temperature interval (cold: $\mathrm{T}<-38^{\circ} \mathrm{C}$, warm: $-38 \leq \mathrm{T}<-23^{\circ} \mathrm{C}$ ). $\mathrm{NH}-\mathrm{cold}$ (a-c), NH-warm (d-f), SH-cold (g-i), SH-warm (j-l). Note the different color scales.

number density has been reached the cloud will move from right to left without changing the number density while the relative humidity relaxes to ice saturation. With this simple cirrus evolution scenario we expect the highest crystal number densities and highest relative humidities to be associated with the highest updraft velocities which is consistent with results of Seifert et al. (2004).

If all clouds were the same and had the same evolution we would simply have a line moving from lower right, across the figure, and exiting in the lower left. We know that clouds are different, but if there is something like a "typical" cloud we would be able to see this in our data as a preferred pathway. For this purpose the number of observations in each Ncvi, RHi pair was normalized to the maximum number of observations for each given RHi. In other words, along a constant $\mathrm{RHi}$, the maximum number of observations is normalized to one. The result is plotted in Fig. 1b. If there is a preferred pathway (evolution, life cycle) for cirrus clouds, this should show up in the diagram as a coherent feature where the normalized maxima are linked adjacently. This is also what we find in the frames of Fig. $1 \mathrm{~b}$ as well as in the corresponding plots for the other data set (Figs. for $\mathrm{NH}$ warm and $\mathrm{SH}$ cold/warm not included).

Having introduced the concept of the Ncvi/RHi diagram we proceed and interpret the thermal composition of the aerosol involved in cirrus formation in the light of the lifecycle of cirrus clouds.

\subsection{Thermal composition of residual particles}

Figure 2 shows the average fraction of volatile, semi-volatile and non-volatile residual particles as a function of Ncvi and $\mathrm{RHi}$, separated into campaign and temperature intervals. The figure is organized in panels as follows: particle types in columns and temperature intervals and campaigns in rows. The first row (panels a-c) represents the NH cold temperature regime data, the second row (panels $\mathrm{d}-\mathrm{f}$ ) represents the $\mathrm{NH}$ warm temperature regime data, the third row (panels g-i) represents the SH cold temperature regime data and finally, the fourth row (panels $\mathrm{j}-1$ ) represents the $\mathrm{NH}$ warm temperature data. 
If neighboring combinations of RHi and Ncvi were uncorrelated, we would expect to observe a mosaic pattern without any coherent structures. Clearly the color patterns in most panels of Fig. 2 display regions with similar color coding. Note that there are many cells lacking data in the warm temperature panels, which is due to the fact that less than $20 \%$ of all our cirrus observations were made above.

The color coding of the volatile particles (left column of panels) shows fractions typically above $50 \%$. The gradient from warm to cold colors indicates that the volatile fraction decreases mainly with increasing Ncvi but also slightly with increasing RHi. The two NH panels and the warm SH panel are very similar in appearance whereas the cold SH panel stands out in comparison. The colors in the cold SH panel are not as warm as in the other three panels and there are gradients in the color coding towards both higher and lower Ncvi.

The color coding of the semi-volatile particles (center column of panels) shows fractions typically less than $10 \%$. In contrast to the volatile fractions there are no clear gradients in color coding apparent for the NH cold case and both $\mathrm{SH}$ cases. For the NH warm case there is a suggestion of relatively higher fractions at high Ncvi and high RHi coordinates.

Due to the relatively small semi-volatile fractions, the nonvolatile fraction (right column of panels) is essentially a complement to the volatile fraction. The similarity between the two NH panels and the warm SH panel is perhaps more obvious in the case of the non-volatile fraction. The difference between high and low relative humidity is pronounced in the two cold cases. As the humidity increases, the fraction of non-volatile particles increases.

The data in the first and third row of Fig. 2 consists only of data sampled at temperatures below $-38^{\circ} \mathrm{C}$. According to theory this temperature range should be dominated by homogeneous freezing of solution droplets formed on soluble cloud condensation nuclei (CCN). It is therefore somewhat unexpected to find that typically 10 to $30 \%(\mathrm{NH})$ and 30 to $40 \%(\mathrm{SH})$ of the residual particles are of non-volatile nature and at high Ncvi the non-volatile residual fraction corresponds to as much as 30 to $40 \%(\mathrm{NH})$ and 40 to $50 \%$ (SH). In the warmer temperature interval the fraction of non-volatile residuals was typically between 10 to $30 \%(\mathrm{NH})$ and 20 to $40 \%$ ( $\mathrm{SH})$. We note that the cold NH case shares more features with the two warm cases than with the cold SH case.

The fraction of ambient aerosol particles incorporated in the ice crystals is small and typically less than $1 \%$ (Seifert et al., 2003a). Therefore, nucleation scavenging is not expected to significantly affect the ambient aerosol. Treating the ambient aerosol in the same fashion as the crystal residues provides us with a possibility to compare the phase partitioning of volatile, semi-volatile and non-volatile particles. In the next section we proceed by presenting the ambient aerosol analogously to the crystal residues in Fig. 2.

\subsection{Thermal composition of interstitial aerosol particles}

In Fig. 3 the volatile, semi-volatile and non-volatile fractions for the non-activated interstitial aerosol are shown, divided into campaign and temperature interval. As pointed out for the residual particle data presented above, if neighboring cells or combinations of RHi and Ncvi were not related we would expect to observe a pattern without any coherent structures.

Volatile particles (left column of panels) typically correspond to more than $50 \%$ of the particles in the NH. The volatile fractions in the SH display warmer colors corresponding to an about 10 and 20 percent units higher fraction for the cold and warm case, respectively. Of the four panels to the left, the SH warm case stands out a little with generally warmer colors throughout the domain. Semi-volatile particles (center column of panels) were below $30 \%$ in the two $\mathrm{NH}$ cases and the $\mathrm{SH}$ cold case, whereas in the $\mathrm{SH}$ warm case this fraction was typically below $20 \%$. The non-volatile fraction (right column of panels) was typically below $15 \%$ in both hemispheres, with the exception of the SH warm case where the non-volatile fraction was less than 5\%.

The panels presented in Fig. 3 lack distinct gradients in color coding as can be seen in most panels of Fig. 2. However, some noticeable features are evident in particular for the cold cases. In the NH data high Ncvi is associated with a relatively high fraction of non-volatile particles. The semivolatile fraction in the $\mathrm{SH}$ cold case, on the other hand, is found to be low at high Ncvi, with the opposite holding true for the $\mathrm{NH}$ semi-volatile fraction.

We use the data presented in Fig. 2 and 3 to study if there is a relation between the properties of the ambient aerosol and the particles incorporated into cirrus crystals.

3.4 Relation between thermal properties of ambient aerosols and residual particles from ice crystals

If one compares the panels of the residual and interstitial particles, it becomes obvious that the relative contributions of the volatile, semi-volatile and non-volatile particles differ significantly. In the cold cases the non-volatile fraction in residual particles is about $15(\mathrm{NH})$ and $30(\mathrm{SH})$ percent units higher than in the out of cloud total aerosol population. In the two warm cases this enrichment corresponds to 15 to 25 and 25 to 35 percent units for the $\mathrm{NH}$ and $\mathrm{SH}$, respectively. The opposite relation is true for the semi-volatile fractions.

To make the relation between crystal residues and ambient aerosol particles clearer we narrow our data set to only include the mature stage of the cloud and exclude the most transient parts of the cloud evolution. To do this we use data where the relative humidity over ice is in the range of 95 and $105 \%$.

The resulting data is then classified according to Ncvi in bins and the average volatile, semi-volatile and non-volatile residual and interstitial fractions are calculated. In Fig. 4 the 

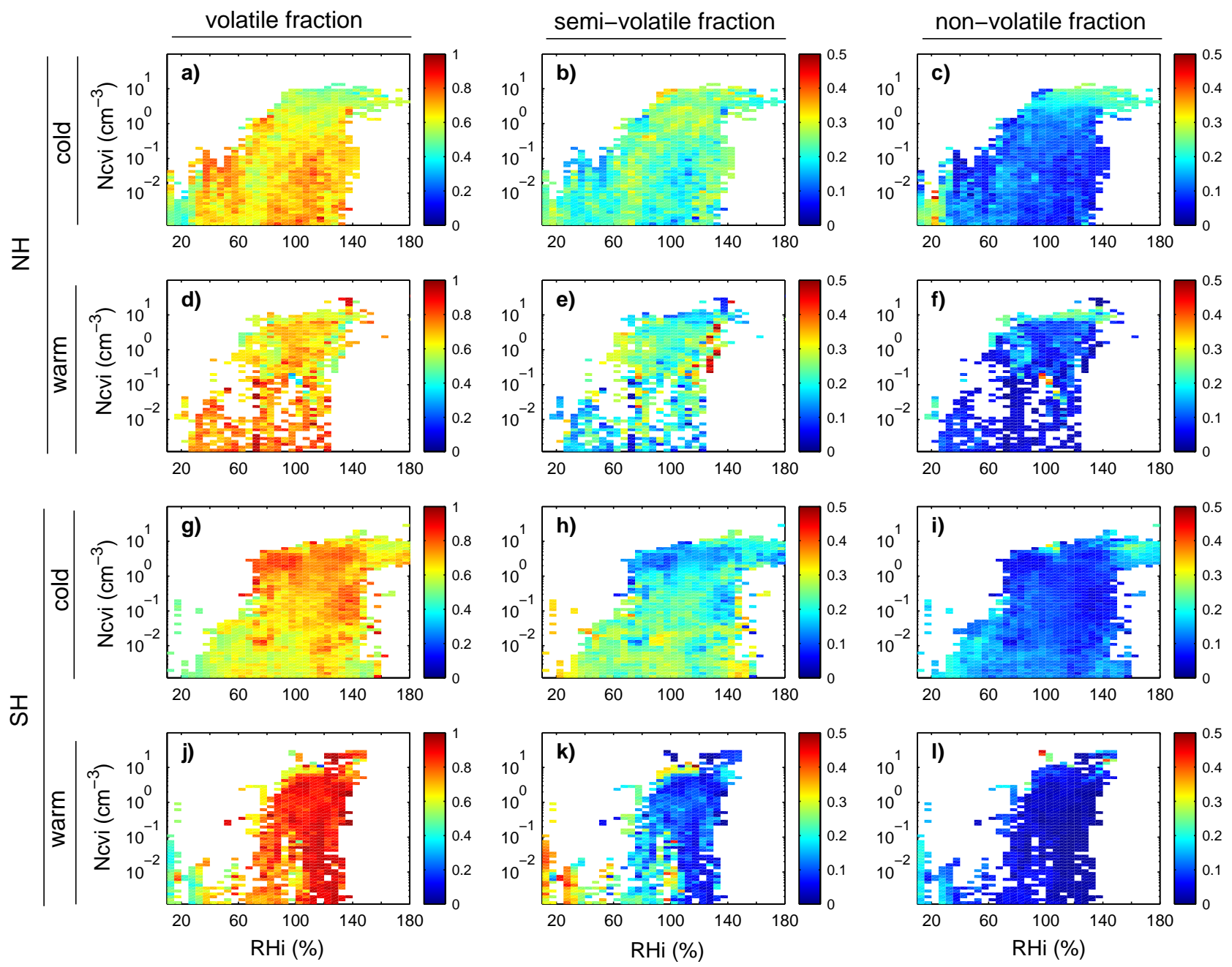

Fig. 3. Average volatile (left column), semi-volatile (middle column) and non-volatile (right column) interstitial aerosol fraction as a function of RHi and Ncvi. Data divided into campaign ( $\mathrm{NH}, \mathrm{SH}$ ) and temperature interval (cold: $\mathrm{T}<-38^{\circ} \mathrm{C}$, warm: $-38 \leq \mathrm{T}<-23^{\circ} \mathrm{C}$ ). $\mathrm{NH}-$ cold $(\mathbf{a}-\mathbf{c})$, NH-warm $(\mathbf{d}-\mathbf{f})$, SH-cold $(\mathbf{g}-\mathbf{i})$, SH-warm $(\mathbf{j}-\mathbf{l})$. Note the different color scales.

fractions are plotted as the relative deviation from the mean fraction calculated for the humidity range 95 to $105 \%$.

In the case of the $\mathrm{NH}$ cold data, the volatile, semi-volatile and non-volatile fractions of the residual and interstitial particles covariate in their deviations from the mean as a function of Ncvi. The NH warm interstitial aerosol fractions suffer from lack of data, but in the warm temperature regime we find the non-volatile residual fraction to increase with crystal number density, much like in the case of cold data. However, only in the NH data the interstitial trends are close to the trends of the residual data. We note that the deviations from the mean are generally smaller in the SH data, which is especially true for the interstitial non-volatile data showing no response to changes in crystal number density.

To summarize, in the $\mathrm{NH}$ cold case there is a clear relation between the respective fractions of particles in the ambient air and the fractions of the residual particles. The volatile fraction decreases with increasing crystal number density, whereas the semi-volatile and the non-volatile fractions increase with increasing Ncvi.

Vertical wind and temperature are important in controlling the crystal number density in cirrus (Kärcher and Ström, 2003). Nevertheless, in the NH the non-volatile particle fraction in crystals and in the ambient air is related to crystal number densities. If the non-volatile fractioning of the crystal residues increases due to an increase in the ambient aerosol non-volatile fraction, or if there is simply a causal relation between crystal number densities and the fractioning of particle types, is not known. However, the fact remains that the $\mathrm{NH}$ data and the SH data show distinctively different behavior when it comes to the fractioning of particle types in ice crystals and interstitial air. 

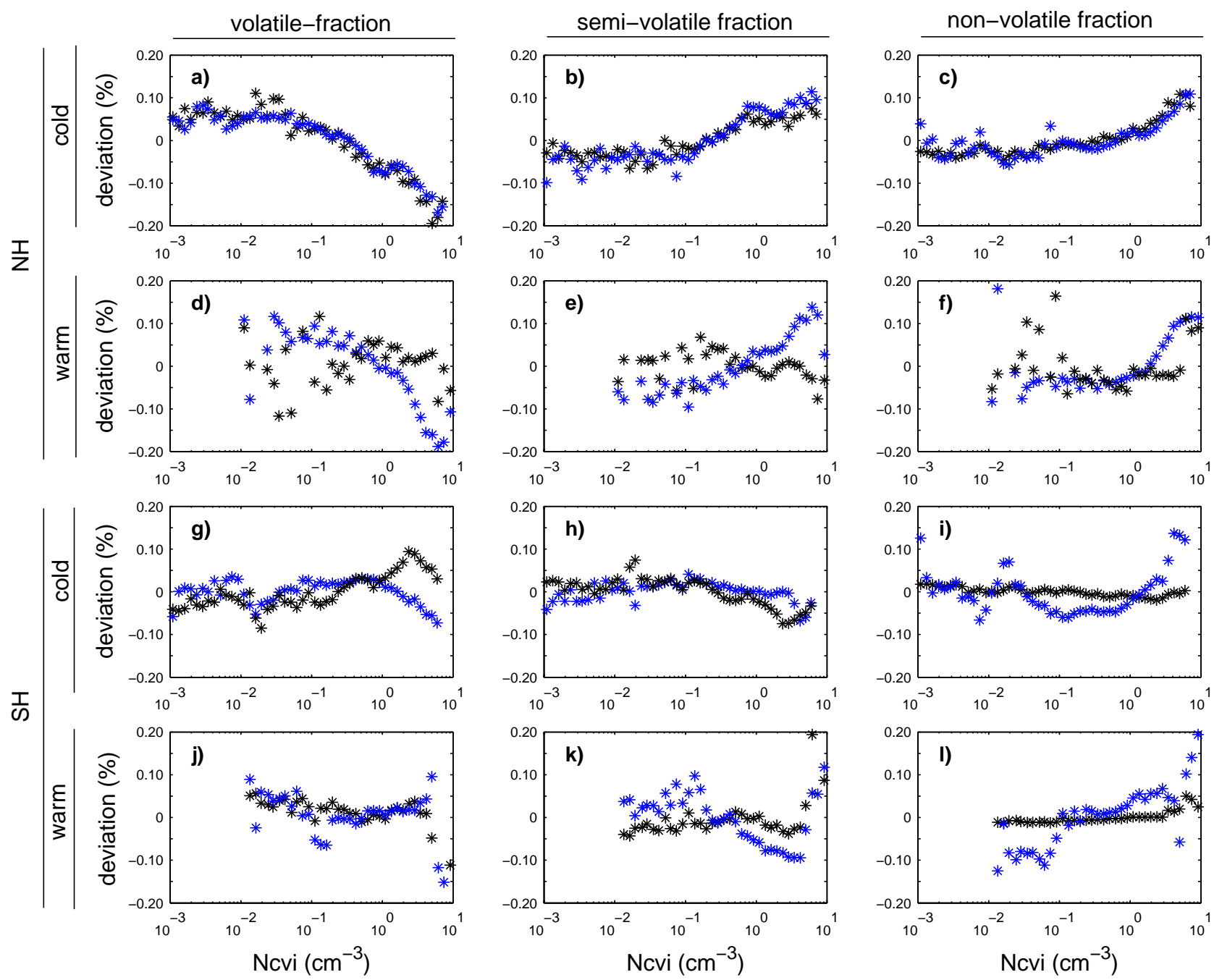

Fig. 4. Deviation from the average volatile (left column), semi-volatile (middle column) and non-volatile (right column) particle fraction as a function of Ncvi shown as blue stars for the residuals and black stars for the interstitial aerosol. Data divided into campaign (NH, SH) and temperature interval (cold: $\mathrm{T}<-38^{\circ} \mathrm{C}$, warm: $\left.-38 \leq \mathrm{T}<-23 \mathrm{~K}\right)$. NH-cold (a-c), NH-warm (d-f), SH-cold (g-i), SH-warm (j-l).

\section{Discussion}

Our observations clearly show an enhancement of the nonvolatile fraction of the residual particles compared to the interstitial aerosol. Typically 10 to $30 \%(\mathrm{NH})$ and 30 to $40 \%$ (SH) of the residual particles are non-volatile at temperatures below $-38^{\circ} \mathrm{C}$. The semi-volatile fraction is typically low, essentially making the volatile and the non-volatile fractions into complements. The highest fractions of non-volatile residual particles were found at high crystal number densities and high relative humidities. Of the four cases ( $\mathrm{NH}$ warm and cold, and SH warm and cold) the SH cold case presented the highest fractions. The other three cases presented smaller values, but at the same time they also had more points of similarity.
At temperatures below $-38^{\circ} \mathrm{C}$ homogeneous freezing is believed to be the dominant mode of ice nucleation. Nevertheless at high crystal number densities as much as 30 to $40 \%(\mathrm{NH})$ and 40 to $50 \%(\mathrm{SH})$ of the particles in cirrus crystals remain after heating the sample air to $250^{\circ} \mathrm{C}$. This is a somewhat surprising result given that the non-volatile fraction had anything to do with the mode of freezing. Based on homogeneous nucleation theory the water activity of a particle will determine the probability of spontaneous freezing (Koop et al., 2000). Large particles composed of hygroscopic material will thus have a higher probability of freezing than small particles. Aerosol particles acting as $\mathrm{CCN}$ in the upper troposphere are believed to mainly consist of varying mixtures of $\mathrm{NH}_{3}, \mathrm{H}_{2} \mathrm{SO}_{4}$ and $\mathrm{H}_{2} \mathrm{O}$. These are compounds that are not stable at $250^{\circ} \mathrm{C}$ and particles composed of them will evaporate and not be detected by the particle counters. Thus, a larger fraction of non-volatile particles (by number that is 
studied here) as observed for high crystal number densities would suggest less hygroscopic material present in the particles, which is the property directly linked to water uptake by the particles.

Murphy (2003) has suggested that a possible source of artifact may arise from impaction of ice crystals (and other large particles) onto the interior surfaces of the sample inlet. The hypothesis is that submicron stainless steal (probe material) particles are abraded from the probe due to the forces when ice crystals impact on the probe. Such particles would be classified as non-volatile in our measurements and thus could potentially affect the results. We have thoroughly considered this potential problem and assessed the possible impact. The large fraction of metal particles observed by Murphy using a device similar to our CVI coupled to PALMS instrument (Thomson et al., 2000), concerns particle sizes larger than about $200 \mathrm{~nm}$ in diameter. Because more than $90 \%$ of the crystal residues are smaller than the detection limit of the PALMS instrument, the observations by Murphy can only be suggestive for the particle composition below the instrument detection limit. We do not know the composition of residual particles smaller than $200 \mathrm{~nm}$ in size. What regards larger sizes we compiled available data where metal signatures have been observed in residual particles and compared it to filter data from the INCA experiment (unpublished and preliminary). Based on our INCA data we arranged data from the other studies (Heintzenberg et al. (1996), Petzold et al. (1998), Twohy and Gandrud (1998), Twohy (2003)) in such way that it could be compared with our results. A detailed comparison revealed that for particles types close to the composition of pure stainless steal (particles containing $\mathrm{Fe}, \mathrm{Cr}$ and $\mathrm{Ni}$, but no $\mathrm{Si}, \mathrm{S}, \mathrm{Cl}, \mathrm{Na}$, or $\mathrm{Al}$ ) we find an abundance of less than 5\% (Seifert et al., 2003b). It is difficult to understand how stainless particles would mix with any other material during the impact by the crystal. Therefore, particles with metal signature mixed with anything else than trace amounts of $\mathrm{Si}, \mathrm{Na}, \mathrm{Ca}, \mathrm{Al}$ etc. are not likely a product of crystal impact.

The data presented by Seifert et al. (2003a) shows that there is no strong preference for ice nucleation to occur on large aerosol particles to the extent expected for homogeneous nucleation (e.g. Heymsfield and Sabin, 1989; DeMott et al., 1994; Jensen et al., 1998). Aerosol particles acting as heterogeneous IN may be crustal, metallic, carbonaceous or even meteoritic material (DeMott et al. 2003; Murphy et al., 1998; Strawa et al. 1999; Sheridan et al., 1994), in other words, chemical species that are likely to remain after heating to $250^{\circ} \mathrm{C}$. Our observations require that at high crystal number densities about 5 non-volatile particles per $\mathrm{ccm}$ air are incorporated into ice crystals. Clearly this is a rather high value, but the ambient number densities of non-volatile particles are always much higher than the number densities of residual particles. Furthermore we would like to point out that even the remains of organic material at $250^{\circ} \mathrm{C}$ are characterized as non-volatile by our thermal denuder system.
The importance of heterogeneous nucleation compared to the competing homogeneous nucleation depends not only on the number of potent freezing agents, but also on updraft and temperature. Heterogeneous nucleation is believed to become important in weaker updrafts (associated with low $\mathrm{Ncvi}$ ) and at higher temperatures (e.g. Sassen and Benson, 2000). Based on this we expect a larger non-volatile fraction of residual particles at low Ncvi, as well as low non-volatile fractions at cold temperatures. In Fig. 2 we see that low Ncvi is actually associated with relatively low non-volatile ratios in all cases but the $\mathrm{SH}$ warm case. The $\mathrm{NH}$ warm and cold cases and the SH warm case present similar fractions. The SH cold case, however, actually shows much higher nonvolatile fractions than the SH warm case. In other words, more or less the opposite of what was expected is observed if non-volatile particles are associated with heterogeneous IN.

Even if a particle is classified as non-volatile the nucleation mechanism may still be homogeneous if the particle is a mixture of different compounds (volatile and non-volatile), i.e. small non-volatile inclusions might not necessarily affect ice formation in an aerosol particle. Recall that if the particles are composed of volatile material with a small nonvolatile core, then the volatility system will detect them as non-volatile particles. But why is the non-volatile fraction so pronounced in the SH cold case? Recently, Minikin et al. (2003) has shown for the INCA data that the aerosol number density in the $\mathrm{NH}$ is more variable and typically a factor of 2-3 higher than in the SH. According to Williams et al. (2002) who examined aerosol variability as function of particle size, variability can be related to the origin of particles. The authors found that for particles believed to be of terrestrial or oceanic origin, the variability correlated with the average number concentration. For particles that are thought to be formed and grow in the atmosphere through coagulation and condensation anticorrelation was observed, the minimum in variability coinciding with the maximum in the number concentration. Hence one might speculate that in the SH the aerosol properties are more characterized by long-range transport compared to the $\mathrm{NH}$ where sources at the surface may play a larger role. A particle not necessarily suitable for forming an ice crystal may acquire a significant coating of soluble material by condensation and coagulation that transforms the particle to a potential ice-forming particle. When humidity increases the particle may turn into a solution droplet with an insoluble core. However, there is no proof that the Southern Hemisphere aerosol is more internally mixed than that of the Northern Hemisphere, nor has it been shown that aged, coated particles are more efficient IN. The other possibility is that a significant fraction of the non-volatile particles is made up by $\mathrm{NaCl}$ particles. These are very hygroscopic, but would not volatilize at $250^{\circ} \mathrm{C}$. The SH midlatitudes are mainly ocean and a large source of seasalt particles. We know that most of the particles forming ice crystals are smaller than $0.1 \mu \mathrm{m}$ in diameter (Seifert et al., 2003a), which would have to hold for the sea-salt particles 
as well. In laboratory studies Mårtensson et al. (2003) have shown that many small $\mathrm{NaCl}$ particles indeed do form during bubble bursting.

It is possible that the non-volatile residual particles in the SH are chemically different from the non-volatile residual particles in the NH. Direct measurements of the chemistry of the residual particles are required to learn what these nonvolatile particles are composed of.

\section{Summary and Conclusions}

The goal of this study was to investigate the phase partitioning of aerosol particles in cirrus clouds with respect to thermal composition to obtain some indirect information about whether the chemical characteristics of aerosol particles play a role in ice nucleation. The major conclusions of this study are as follows:

1. In the cold temperature regime the non-volatile residual fraction typically corresponds to 10 to $30 \%(\mathrm{NH})$ and 30 to $40 \%$ (SH). In the warm temperature regime the non-volatile residual fraction was typically 10 to $30 \%$ $(\mathrm{NH})$ and 20 to $40 \%(\mathrm{SH})$. At high crystal number densities the non-volatile fraction was even higher and in the range of 30 to $40 \%(\mathrm{NH})$ and 40 to $50 \%(\mathrm{SH})$ for both temperature regimes.

2. The semi-volatile residual fraction was typically small, less than $10 \%$, essentially causing the volatile and the non-volatile fractions to be complements.

3. Compared to the ambient aerosol particles, the fraction of non-volatile particles is enriched in the crystal residuals by $15(\mathrm{NH})$ and $30(\mathrm{SH})$ percent units in the cold cases. For the two warm cases this enrichment corresponds to 15 to $25(\mathrm{NH})$ and 25 to $35(\mathrm{SH})$ percent units.

4. In the NH cold case there is a clear relation between the fraction of non-volatile particles in the ambient air and the non-volatile fraction of the residual particles. Both increase with increasing crystal number density.

5. The NH cold case has more in common with the $\mathrm{NH}$ and SH warm cases than with the SH cold case. Hence the chemical signature of the residual particles in the $\mathrm{NH}$ appears to be temperature independent.

By coupling a thermal denuder system to a CVI probe we have been able to get some insight into the chemical nature of the numerous small ice crystal residuals. The perhaps unexpectedly large fraction of non-volatile particles, especially at cold temperatures, and the lack of temperature dependence in the NH data, suggests that cirrus formation might not simply be divided into homogenous or heterogeneous modes depending on temperature.

The simple thermal denuder system used in this study is limited by only treating integral number densities. It was not possible to identify the effect of aerosol mixing on cirrus formation, since we can not distinguish between particles which were volatile but have small non-volatile cores and entirely non-volatile particles. Hence the above presented conclusions must be taken with the caveat that the thermal composition of residual and interstitial particles was not measured size dependent. A system that would provide size resolved information would really help in understanding the link between aerosols and cirrus formation. A volatility tandem DMA technique would not only provide size resolved information, but would also give a direct measurement of the internal and external mixture of the aerosol.

Acknowledgements. We acknowledge the work by the flight department at DLR during the campaign. L. Bäcklin and N. Walberg were very helpful in the work with the instruments. We thank B. Noone for solving all kinds of problems and S. Wilhelm for excellent support during the INCA preparation in Oberpfaffenhofen. Helpful discussions with P. Tunved about MATLAB related problems are also acknowledged. This work was supported by the European Union through the INCA project (Contract no. EVK2-CT-1999-00039).

Edited by: T. Koop

\section{References}

Brooks, B. J., Smith, M. H., Hill, M. K., and O’Dowd, C. D.: Sizedifferentiated volatility analysis of internally mixed laboratorygenerated aerosol, J. Aerosol. Sci., 33, 555-579, 2002.

Clarke, A. D.: A Thermo Optic Technique for In situ Analysis of Size-Resolved Aerosol Physicochemistry, Atmos. Envir. Part AGeneral Topics, 25, 635-644, 1991.

DeMott, P. J., Meyers, M. P., and Cotton, W. R.: Parameterization and Impact of Ice Initiation Processes Relevant to NumericalModel Simulations of Cirrus Clouds, J. Atmos. Sci., 51, 77-90, 1994.

DeMott, P. J., Rogers, D. C., and Kreidenweis, S. M.: The susceptibility of ice formation in upper tropospheric clouds to insoluble aerosol components, J. Geophys. Res., 102, 19575-19584, 1997.

DeMott, P. J.: Laboratory studies of cirrus cloud processes, in: Cirrus, edited by Lynch, D. K., Sassen, K., Starr, D. O'C., Stevens, G., Oxford Univ. Press, New York, 102-135, 2002.

DeMott, P. J., Sassen, K., Poellot, M. R., Baumgardner, D., Rogers, D. C., Brooks, S. D., Prenni, J. A., and Kreidenweis, S. M.: African dust aerosols as atmospheric ice nuclei, Geophys. Res. Lett., 30, 1732, doi:10.1029/2003GL017410, 2003

Gayet, J. F., Crépel, O., Fournol, J. F., and Oshchepkov, S.: A new airborne Polar Nephelometer for the measurements of optical and microphysical cloud properties. Part I: Theoretical design, Annales Geophysicae, 15, 451-459, 1997.

Gerbig, C., Kley, D., Volz-Thomas, A., Kent, J., Dewey, K., and McKenna, D. S.: Fast response resonance fluorescence CO measurements aboard the C-130: Instrument characterization and measurements made during North Atlantic Regional Experiment 1993, J. Geophys. Res., 101, 29 229-29238, 1996. 
Haag, W., Kärcher, B., Ström, J., Lohmann, U., Ovarlez, J., and Stohl, A.: Freezing thresholds and cirrus cloud formation mechanisms inferred from in situ measurements of relative humidity, Atmos. Chem. Phys., 3, 1791-1806, 2003.

Heymsfield, A. J. and Sabin, R. M.: Cirrus Crystal Nucleation by Homogeneous Freezing of Solution Droplets, J. Atmos. Sci., 46, 2252-2264, 1989.

Heintzenberg, J., Okada, K., and Ström, J.: On the composition of non-volatile material in upper tropospheric aerosols and cirrus crystals, Atmos. Res., 41, 81-88, 1996.

Jensen, E. J., Toon, O. B., Tabazadeh, A., Sachse, G. W., Anderson, B. E., Chan, K. R., Twohy, C. W., Gandrud, B., Aulenbach, S. M., Heymsfield, A., Hallett, J., and Gary, B.: Ice nucleation processes in upper tropospheric wave-clouds observed during SUCCESS, Geophys. Res. Lett., 25, 1363-1366, 1998.

Koop, T., Luo, B. P., Tsias, A., and Peter, T.: Water activity as the determinant for homogeneous ice nucleation in aqueous solutions, Nature, 406, 611-614, 2000.

Kärcher, B. and Lohmann, U.: A parameterization of cirrus cloud formation: Heterogeneous freezing, J. Geophys. Res., 108, 10.1029/JD2002003220, 2003.

Kärcher, B. and Ström, J.: The roles of dynamical variability and aerosols in cirrus cloud formation, Atmos. Chem. Phys., 3, 823838, 2003.

Minikin, A., Petzold, A., Ström, J., Krejci, R., Seifert, M., Velthoven, P., Schlager, M., and Schumann, U.: Aircraft observations of the upper tropospheric fine particle load in the northern and southern hemispheres at midlatitudes, Geophys. Res. Lett., 30, doi: 10.1029/2002GL016458, 2003.

Murphy, D. M., Thomson, D. S., and Mahoney, T. M. J.: In situ measurements of organics, meteoritic material, mercury, and other elements in aerosols at 5 to 19 kilometers, Science, 282, 1664-1669, 1998.

Murphy, D. M.: Sampling in Ice Clouds, presentation at the Crystal Face workshop, available at http://cloud1.arc.nasa.gov/ crystalface/postpresentations.html, 2003.

Mårtensson, E. M., Nilsson, E. D., de Leeuw, G., Cohen, L. H., and Hansson, H. C.: Laboratory simulations and parameterization of the primary marine aerosol production, J. Geophys. Res., in press 2003.

Noone, K. J., Ogren, J. A., Heintzenberg, J., Charlson, R. J., and Covert, D. S.: Design and Calibration of a Counterflow Virtual Impactor For Sampling of Atmospheric Fog and Cloud Droplets, Aerosol Sci. Technol., 8, 235-244, 1988.

Ogren, J. A., Heintzenberg, J., and Charlson, R. J.: In-situ sampling of clouds with a droplet to aerosol converter, Geophys. Res. Lett., 12, 121-203, 1985.

Ovarlez, J., van Velthoven, P., Sachse, G., Vay, S., Schlager, H., and Ovarlez, H.: Comparison of water vapor measurements from POLINAT 2 with ECMWF analyses in high-humidity conditions, J. Geophys. Res., 105, 3737-3744, 2000.

Petzold, A., Ström, J., Ohlsson, S., and Schröder, F.: Elemental composition and morphology of ice-crystal residual particles in cirrus clouds and contrails, Atmos Res, 49, 21-34, 1998.
Sassen, K. and Benson, S.: Ice nucleation in cirrus clouds: A model study of the homogeneous and heterogeneous modes, Geophys. Res. Lett., 27, 521-524, 2000.

Schlager, H., Konopka, P., Schulte, P., Schumann, U., Ziereis, H., Arnold, F., Klemm, M., Hagen, D. E., Whitefield, P. D., and Ovarlez, J.: In situ observations of air traffic emission signatures in the North Atlantic flight corridor, J. Geophys. Res., 102, 10739-10750, 1997.

Schröder, F. and Ström, J.: Aircraft measurements of sub micrometer aerosol particles $(>7 \mathrm{~nm})$ in the midlatitude free troposphere and tropopause region, Atmos. Res., 44, 333-356, 1997.

Sheridan, P. J., Brock, C. A., and Wilson, J. C.: Aerosol-particles in the upper troposphere and lower stratosphere-elemental composition and morphology of individual particles in the northern midlatitudes, Geophys. Res. Lett., 21, 2587-2590, 1994.

Seifert, M., Ström, J., Krejci, R., Minikin, A., Petzold, A., Gayet, J.F., Schumann, U., and Ovarlez, J.: In situ observations of aerosol particles remaining from evaporated cirrus crystals: Comparing clean and polluted air masses, Atmos. Chem. Phys., 3, 10371049, 2003a.

Seifert, M., Ström, J., Krejci, R., Minikin, A., Petzold, A., Gayet, J.-F., Schlager, H., Ziereis, H., Schumann, U., and Ovarlez, J.: Aerosol-cirrus interactions: A number based phenomenon at all?, Atmos. Chem. Phys., 4, 293-305, 2004.

Seifert, M., Ström, J., Krejci, R., Minikin, A., Petzold, A., Gayet, J.-F., Schlager, H., Ziereis, H., Schumann, U., and Ovarlez, J.: Interactive comment on "Thermal stability analysis of particles incorporated in cirrus crystals and of non-activated particles in between the cirrus crystals: Comparing clean and polluted air masses" by M. Seifert et al., Atmos. Chem. Phys. Discuss., 3, S2352-S2362, 2003b.

Strawa, A. W., Drdla, K., Ferry, G. V., Verma, S., Pueschel, R. F., Yasuda, M., Salawitch, R. J., Gao, R. S., Howard, S. D., Bui, P. T., Loewenstein, J. W., Elkins, J. W., Perkins, K., and Cohen, R.: Carbonaceous aerosol (Soot) measured in the lower stratosphere during POLARIS and its role in stratospheric photochemistry, J. Geophys. Res., 104, 26 753-26 766, 1999.

Ström, J., Seifert, M., Krejci, R., Minikin, A., Petzold, A., Auriol, F., Ovarlez, J., and Schumann, U.: A statistical approach to a Lagrangian perspective of cirrus evolution based on data from the INCA experiments in the northern and southern hemisphere midlatitudes. Procceedings of the AMS conference on Cloud Physics, Odgen Utah, p. 6.3, 2002.

Thomson, D. S., Schein, M. E., and Murphy, D. M.: Particle analysis by laser mass spectrometry WB-57F instrument overview, Aerosol Sci. Technol., 33, 153-169, 2000.

Twohy, C. H. and Gandrud, B. W: Electron microscope analysis of residual particles from aircraft contrails, Geophys. Res. Lett., 25, $1359-1362,1998$

Twohy, C. H. and Gandrud, B. W.: Electron microscope analysis of residual particles from aircraft contrails, Geophys. Res. Lett., 25, 1359-1362, 1998.

Williams, J., de Reus, M., Krejci, R., Fischer, H., and Ström, J.: Application of the variability-size relationship to atmospheric aerosol studies: estimating aerosol lifetimes and ages, Atmos. Chem. Phys., 2, 133-145, 2002 